DOI 10.31489/2019No2/43-47

UDC 621.9.048.7; 691.175.5.8

\title{
IMPACT RESEARCH OF ELECTRON BEAM PROCESSING ON THE STRUCTURE AND PROPERTIES OF PA6 POLYAMIDE
}

\author{
Rakhadilov B.K ${ }^{1}$., Sagdoldina Zh.B. ${ }^{1}$, Ocheredko I.A. ${ }^{1}$, Kombaev K.K. ${ }^{2}$, Khassenov A.K. ${ }^{3}$ \\ 1S. Amanzholov East Kazakhstan State University, Ust-Kamenogorsk, Kazakhstan, sagdoldina@mail.ru \\ 2D. Serikbayev East Kazakhstan State Technical University, Ust-Kamenogorsk, Kazakhstan \\ ${ }^{3}$ E.A. Buketov Karaganda State University, Karaganda, Kazakhstan
}

\begin{abstract}
In this work we studied the impact of electron irradiation with energy of $1.3 \mathrm{MeV}$ on the structure and properties of PA6 polyamide. Irradiation doses ranged from 50 to $500 \mathrm{kGy}$. The results of research presented that irradiation with small doses of PA6 polymer is able to increase the mechanical characteristics, while irradiation with large doses significantly reduces them. Wear resistance decreases under irradiation conditions from $350 \mathrm{kGy}$, and the hardness of the samples varies slightly. The polymer structure was studied by X-ray diffractometry and IR spectroscopy. Electron irradiation at an energy of $1.3 \mathrm{MeV}$ did not lead to a change in the crystalline form of the PA6 polymer, but caused partial crystalline damage. The peak intensity of the $\alpha$-phase after electron irradiation increases compared with the unirradiated sample. It may be due to an increase in the crystallinity of the polymer.
\end{abstract}

Keywords: electron irradiation, polyamide, wear resistance, hardness, structure.

\section{Introduction}

Development of modern science and technology is unthinkable without polymeric materials using. Expanding the scope of application of polymeric materials required the creation on its basis of new materials with a given set of properties capable of processing into products using highperformance methods. The great interest in radiation methods is due to the fact that their use in industry instead of traditional methods of material modification (such as chemical modification methods using solvents and a long processing time, etc.) leads to significant savings resources, energy, increasing production efficiency, significant reducing the environmentally harmful effects of production.An important circumstance is also that in a number of cases, electron-beam processing allows one to obtain structural-phase states of materials that are not realized with traditional processing methods [1]. Intermediate formations appear under irradiation with beams of charged particles in polymers which high reactive - free radicals, ions, excited molecules. They are sources of further chemical transformations, leading to changes in the chemical structure, and consequently the properties of polymers.

In particular, transverse intermolecular and intramolecular bonds are formed under the activity of radiation in polymers - bond breaking processes occur in the main chain and side groups, grafting reactions, oxidation, etc. vinyl and vinylidene and vinylidene groups appears decompose and formation, as well as isomerization, cyclization [2].For example, the structuring (crosslinking) of molecules increases the mechanical strength and heat resistance of polyethylene under the radiation modification of polyethylene. Irradiated wires and cables with polyethylene insulation can be operated at higher temperatures (current loads) [3].

In work [4] was presented that the mechanical characteristics are closely related to the modification of the structure formed after electron irradiation. An increase in the wear resistance of polymeric materials is associated with the creation of a large number of cross-links upon irradiation with an electron beam. The results obtained in work [5] confirmed that crosslinking at significant doses prevails over depolymerization, even if irradiation was performed in air. In this regards the 
aim of this work is to study the impact of electron irradiation on the structure and properties of PA6 polyamide.

\section{Materials and methods of research}

Electron beam irradiation of the samples was carried out on an ELV-4 industrial electron accelerator. Electron irradiation mode: beam energy $1.3 \mathrm{MeV}$, amperage beam $12 \mathrm{~mA}$, conveyor speed $3.5 \mathrm{~m} / \mathrm{min}$ and radiation doses of 50 and $150 \mathrm{kGy}$. The samples were ground and polished before irradiation. Provisions of samples for research in the form of a circle with a thickness of $3 \mathrm{~mm}$ were cut from a rod of polymers (rod diameter $30 \mathrm{~mm}$ ). The morphology of the polymer samples was studied using a JSM-6490 scanning electron microscope and Solver HV atomic force microscope. Xray diffraction studies of polymer samples were performed on an X'PertPRO diffractometer. The diffraction patterns were recorded using $\mathrm{CuK} \alpha$ radiation $\left(\lambda=2,2897 \mathrm{~A}^{0}\right)$ at a voltage of $40 \mathrm{kV}$ and a current of $30 \mathrm{~mA}$. FTIR-801 Simex Fourier-IR spectrometer was used to research the changes in the chemical composition of the polymers. Samples were studied at a wavelength of $(450-4700) \mathrm{cm}^{-1}$, resolution $1 \mathrm{~cm}^{-1}, \mathrm{t}=25 \mathrm{C}^{0}$.

The hardness of the polymer samples was measured on a TK-2M tool in accordance with GOST 4670-91. The diameter of the ball is $1.58 \mathrm{~mm}$ under the pressure of $100 \mathrm{kgf}$. Tribological sliding friction tests were carried out on a THT-S-BE-0000 tribometer with using the standard ball-disk technique (ASTM G 133-95 and ASTM G 99). A ball with a diameter of $6.0 \mathrm{~mm}$ was used as a counterbodyfrom a certified material $-\mathrm{Al}_{2} \mathrm{O}_{3}$. The experimentwas carried outunder the pressure of 10 $\mathrm{N}$ and a linear velocity of $10.5 \mathrm{~cm} / \mathrm{s}$ with a wear radius of $5 \mathrm{~mm}$ where the friction path was $63.1 \mathrm{~m}$. The wear resistance of PA6 polymer before and after electron irradiation was characterized by the amount of wear.

\section{Results and discussion}

Research of the surface morphology of the PA6polymer which carried out by atomic force microscopy presented that the irradiated surface has a larger surface irregularities (Fig.1.). Since the main effect of medium-energy electron beams on materials is their heating [6], so the most probable reason for the observed change in the surface morphology is the melting of the surface layer with subsequent solidification in a time comparable to the pulse duration. The irregularity of the irradiated surface layers increases with increasing in the radiation dose.
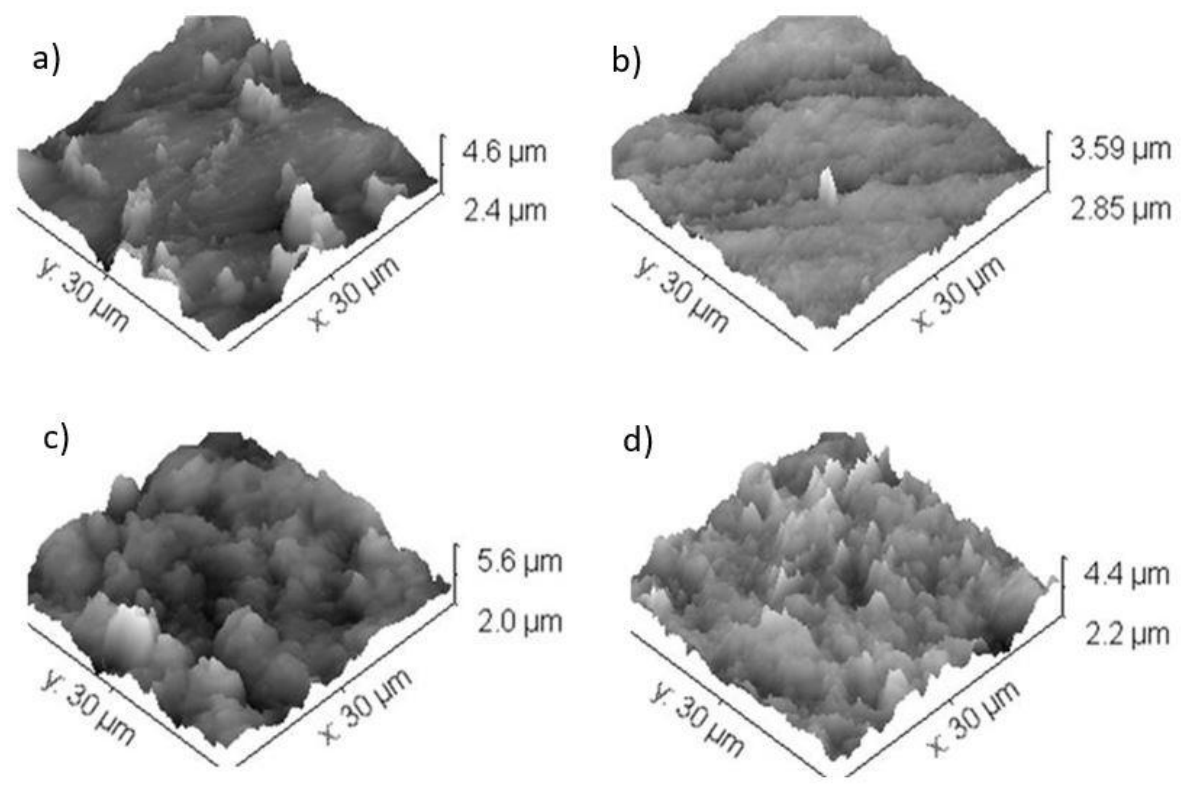

Fig.1. Surface topography of PA6 polymer samples a) initial; b) $150 \mathrm{kGy}$; c) $200 \mathrm{kGy}$; d) $500 \mathrm{kGy}$ 
We have studied changes in the structure of the PA6 polymer after electron irradiation with a dose of 200 and $500 \mathrm{kGy}$. Fig.2presents the results of an x-ray phase analysis of PA6 samples. The diffraction pattern of PA6 polyamide shows two diffraction peaks at $2 \theta=20.5^{\circ}$ and $23.5^{\circ}$, which are a distinctive feature of the $\alpha$-phase of PA6 [7-9]. This explains the crystalline form of polyamide PA6. The peak intensity of $\alpha$ phase increases compared with the unirradiated sample after electron irradiation and this may be due to increasing in the crystallinity of the material. Perhaps the irradiation process accelerated the crosslinking rate of free radicals and restrained pyrolysis and recombination, which lead to increasing in crystallinity.

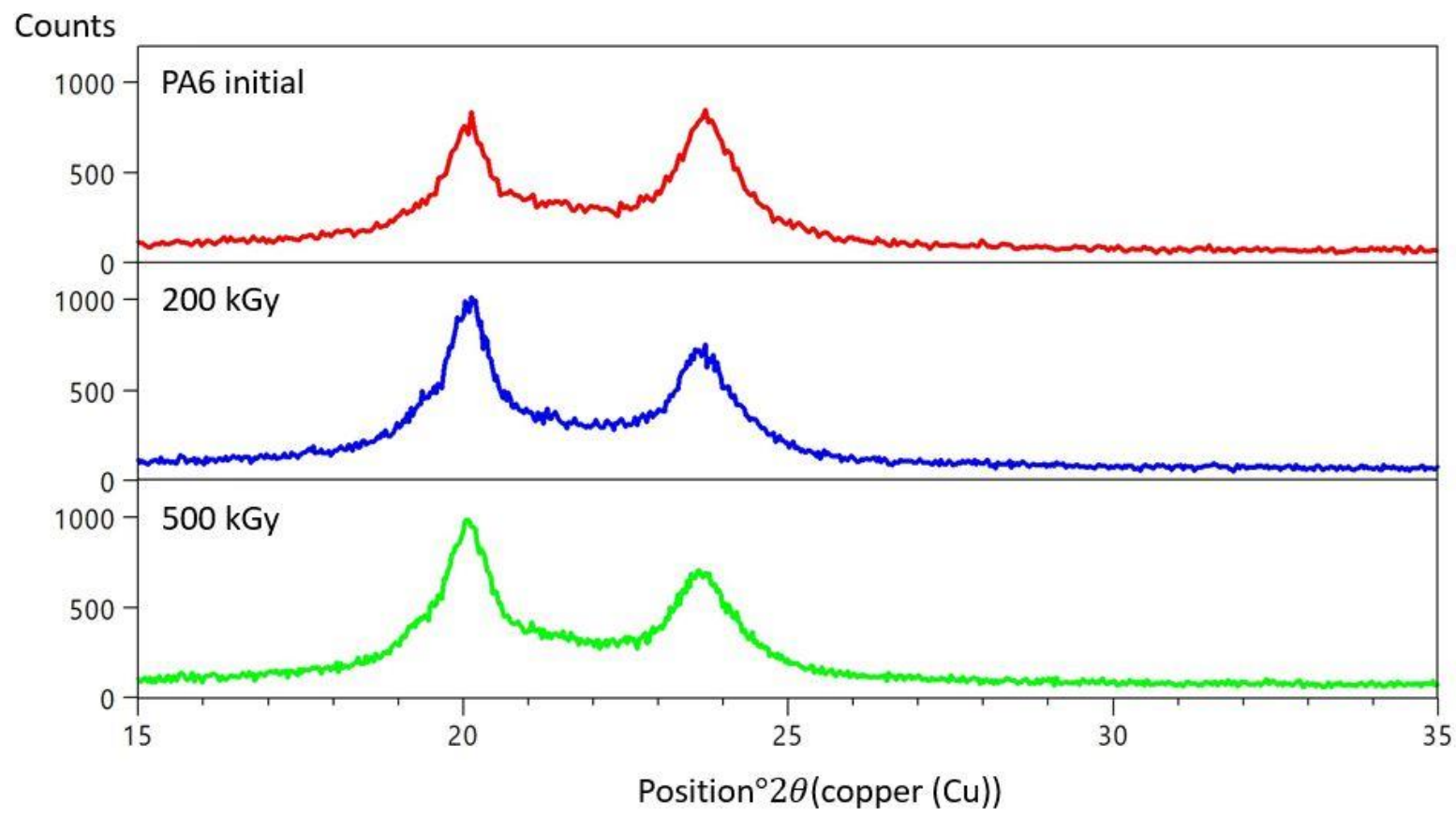

Fig.2.Diffractogram of PA6 samples

Fig.3 shows the infrared spectra of unirradiated and irradiated PA6 samples. The characteristic peaks of the PA6 vibrational frequency are at the level of $3579.4\left(\mathrm{NH}\right.$ stretching), $2934.8\left(\mathrm{CH}_{2}\right.$ stretching), 1585.1 ( $\mathrm{C}=\mathrm{O}$ stretching, amide I), 1398.7 ( $\mathrm{NH}$ bending vibration) and $776.28 \mathrm{~cm}$ ${ }^{1}$ (bending vibration $\mathrm{NH}$ ) [10]. Irradiation did not lead to a change in the crystalline form of the PA6 polymer, but caused partial crystalline defect.

Fig.4presents the surface hardness values of samples of PA6 polymers before and after electron irradiation. Based on the analysis of the obtained results on the determination of hardness, it was found that the hardness largely depends on the radiation dose. The highest hardness value is observed after irradiation with a dose of $50 \mathrm{kGy}$ and $100 \mathrm{kGy}$. Decreasing in hardness is observed at high doses of radiation. Presumably, this is due to its destruction. The results of hardness measurements show that electronic irradiation of the PA6 polymer with small doses can increase the mechanical characteristics, while irradiation with large doses reduces them.

Fig.5shows the amount of wear $\left(\mu \mathrm{m}^{3}\right)$ of PA6 polymer samples after experiment of a "balldisk" scheme. It can be seen that a decrease in the amount of wear is observed after irradiation with a dose of 50to $250 \mathrm{kGy}$ and then at $300 \mathrm{kGy}$ there is an increase in the amount of wear compared to the initial one. A decrease in the wear resistance of the samples with an increase in the radiation dose is probably due to the expansion of the polymer chain upon the absorption of electrons with the formation of crystalline defects [11]. 


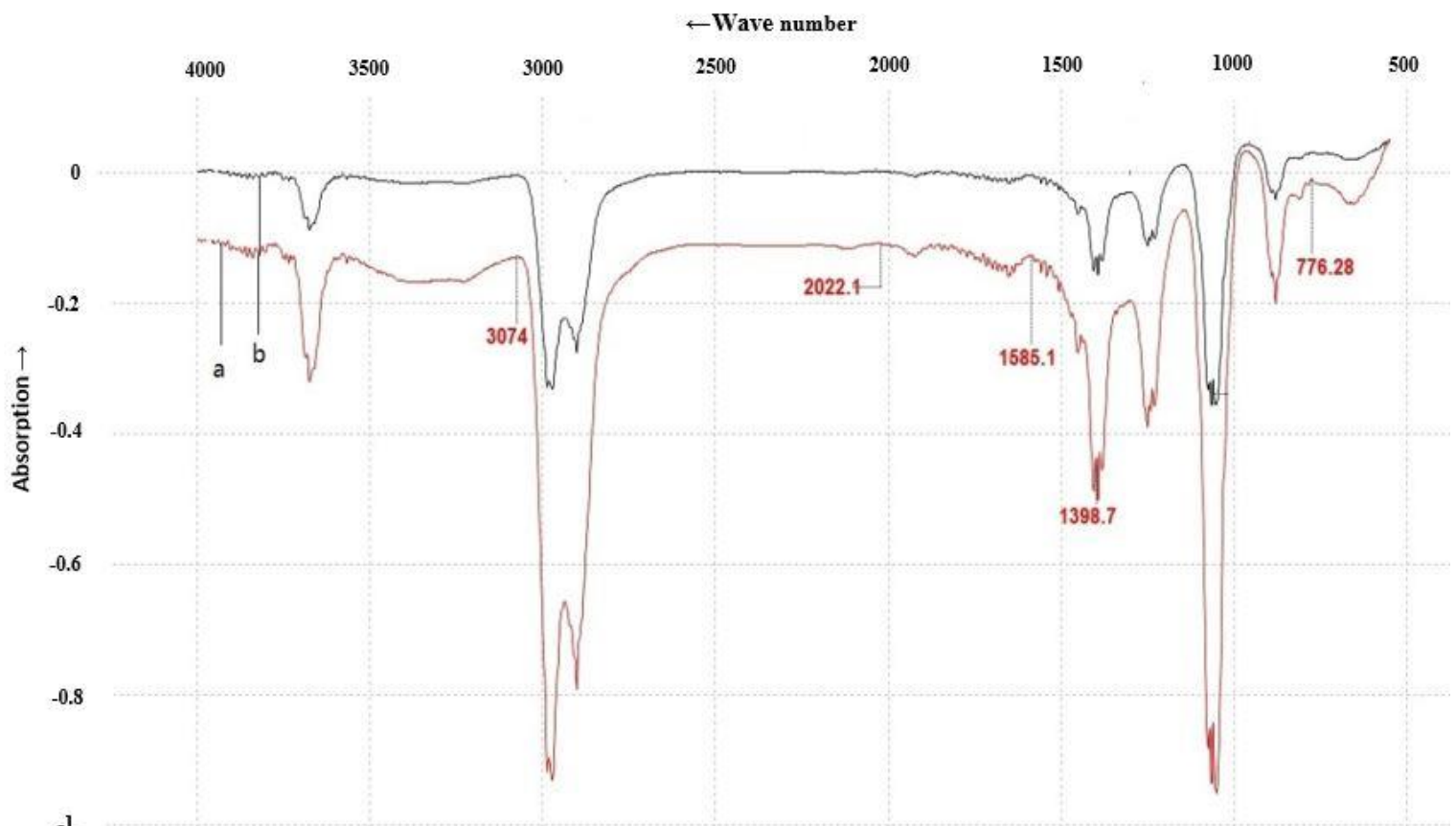

Fig.3. IR spectra of unirradiated (a) and irradiated (b, $150 \mathrm{kGy)} \mathrm{PA6} \mathrm{samples.}$

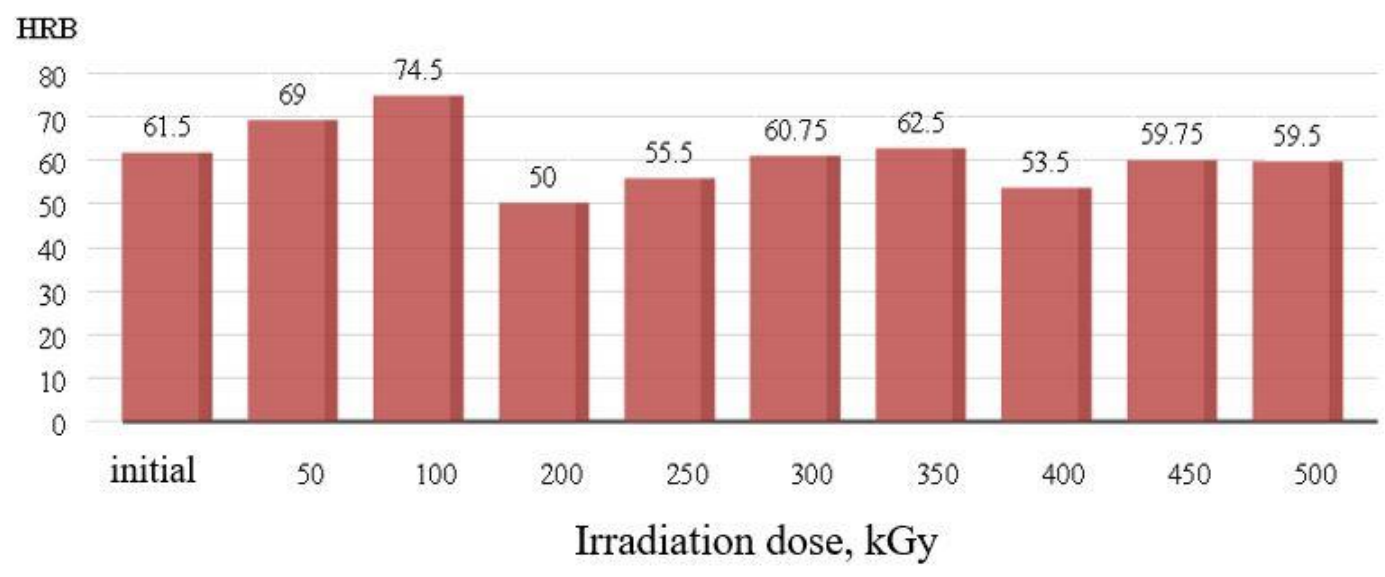

Fig.4. Rockwell hardness of PA6 samples before and after electron irradiation.

PA6

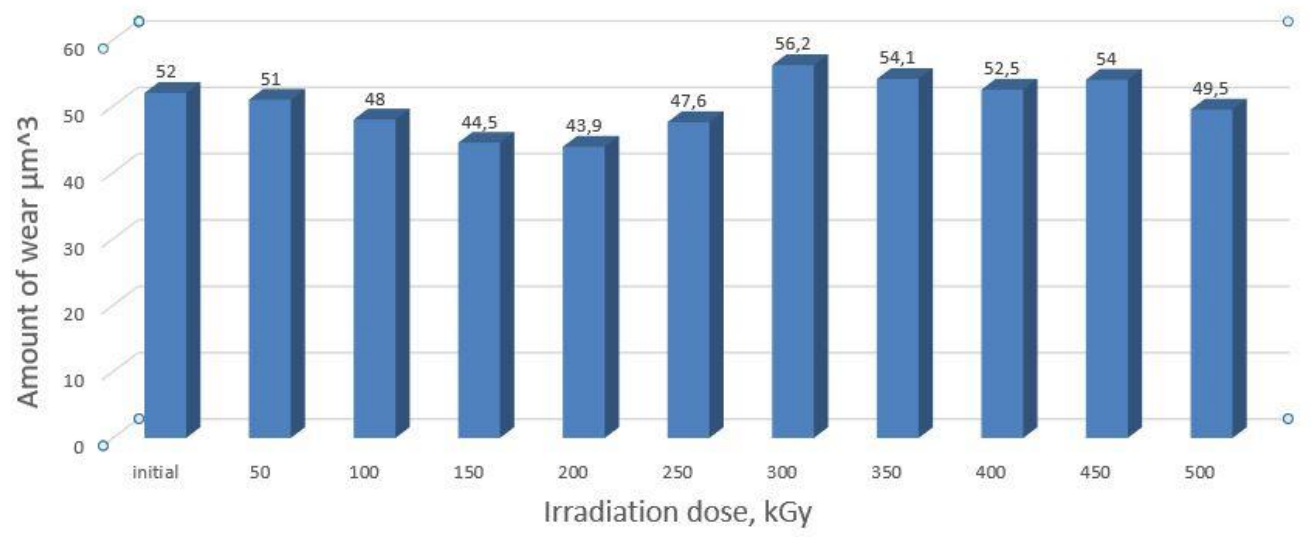

Fig.5. The amount of wear of samples PA6 before and after electron irradiation. 


\section{Conclusion}

Based on the obtained experimental data and their analysis, it can be stated that irradiation with small doses of PA6 polymer can increase the mechanical characteristics, while irradiation with large doses significantly reduces them. Wear resistance decreases under irradiation conditions from $350 \mathrm{kGy}$ at an energy of $1.3 \mathrm{MeV}$. The hardness of the samples varies slightly. However, the characteristic dependence of surface properties on the dose of electron irradiation is difficult to establish on the basis of the results of structural studies, since insignificant changes cannot be a characteristic feature.

It was determined that the irregularity of the irradiated surface layers increaseswith increasing in the irradiation dose. However, in this case, a direct dependence of the micro-roughness of the irradiated surface layers with the amount of wear and the wear coefficient is not observed. This indicates that an increase in the wear resistance (decrease in the amount of wear) of the polymer materials studied after irradiation is not associated with the geometry of the surface, but is associated with structural changes. Conducted research have shown the use of electron beam processing with an energy of $1.3 \mathrm{MeV}$ for PA6 polymers is possible at relatively low doses of electron irradiation (up to $300 \mathrm{kGy}$ ).

\section{Acknowledgment}

This work was financially supported by the Science Committee of the Ministry of Education and Science of the Republic of Kazakhstan under the Grant Financing for Scientific Research program

(Project code - AR05134982)

\section{REFERENCES}

1 Raghu S., Archana K., Sharanappa C., Ganesh S., Devendrappa H. The physical and chemical properties of gamma ray irradiated polymer electrolyte films. Journal of Non-Crystalline Solids. 2015, Vol.426, pp.55- 62 .

2 Pikaev A.K. Novye razrabotki radiatsionnoi tehnologii v Rossii. Himia vysokih energii, 1999, Vol.32, pp. 3 - 11. [in Russian].

3 Sarada I., Ahmad A., Bakar A., et al. Influence of gamma irradiation on polymerization of pyrrole and glucose oxidase immobilization onto poly (pyrrole)/poly(vinyl alchohol) matrix. Applied Surface Science, 2017, Vol.400, pp. 118-128.

4 Visco A.M., Torrisi L., Campo N., et al. Mechanical Performance of Electron-Beam-Irradiated UHMWPE in Vacuum and in Air. J Biomed Mater Res Part B: Appl. Biomater, 2009, 89B, pp. 55 - 64.

5 Slouf M., Synkova H., Baldrian J., Marek A., et al. Structural changes of UHMWPE after e-beam irradiation and thermal treatment. J Biomed Mater Res Part B: Appl.Biomater, 2008, 85B, pp.240 - 251.

6 Shifeng Zhu, Meiwu Shi, Meifang Zhu Effects of Electron-Beam Irradiation Crosslinking on PA6 Fibers. Fibers and Polymers, 2013, Vol.14, No.4, pp.525 - 529.

7 Shifeng Zhu, Meiwu Shi, Meifang Zhu. Effects of Electron-Beam Irradiation Crosslinking on PA6 Fibers. Fibers and Polymers. 2013, Vol.14, No.4, pp.525 - 529.

8 Nalwa H.S. Ferroelectric Polymers. Marcel Dekker, New York, 1995, pp.283 - 286.

9 SibiliaJ.P.A Guide to Material Characterization and Chemical Analysis. VCH Publishers, New York, 1996, pp.148 - 150.

10 Sengupta R., Bandyopadhyay A., Sabharwal S., Chaki T.K. Polyamide-6,6/in situ silica hybrid nanocomposites by sol-gel technique: synthesis, characterization and properties. Polymer, 2005, Vol.46, No.10, pp.3343 - 3354 .

11 Makuuchi K., Cheng S. Radiation Processing of Polymer Materials and Its Industrial Applications, John Wiley \& Sons, Inc., New Jersey (2012). 